\title{
Outcomes and Hemodynamic Performances of Transcatheter Aortic Valve Replacement With Two Generations of Self-expanding Transcatheter Aortic Valves
}

\section{Chia-Cheng Kuo}

Taipei Veterans General Hospital

Hsiao-Huang Chang

Taipei Veterans General Hospital

Hsin-Bang Leu

Taipei Veterans General Hospital

I-Ming Chen

Taipei Veterans General Hospital

Po-Lin Chen

Taipei Veterans General Hospital

Su-Man Lin

Taipei Veterans General Hospital

Ying-Hwa Chen ( $\nabla$ yhchen@vghtpe.gov.tw )

Taipei Veterans General Hospital

\section{Research Article}

Keywords: aortic stenosis, transcatheter aortic valve replacement

Posted Date: October 27th, 2021

DOI: https://doi.org/10.21203/rs.3.rs-953688/v1

License: (c) (1) This work is licensed under a Creative Commons Attribution 4.0 International License. Read Full License 


\section{Abstract}

The aim of this study was to investigate the hemodynamic and clinical performance of the Evolut $R$ compared with its direct predecessor, CoreValve, in Taiwanese population. This study included all consecutive patients who underwent TAVR with either the CoreValve or Evolut R between March 2013 to December 2020. Thirty-day Valve Academic Research Consortium-2 (VARC-2)-defined outcomes and hemodynamic performances were investigated. There were no significant differences in baseline demographic characteristics between patients receiving CoreValve $(n=117)$ or Evolut $R(n=117)$. Aortic valve-in-valve procedures for failed surgical bioprosthesis and procedures under conscious sedation were performed significantly more often with Evolut R. Pre-dilatation was performed significantly more often and contrast media volume was significantly higher with CoreValve. Stroke $(0 \%$ vs $4.3 \%, p=0.024)$ and the need for emergent conversion to open surgery $(0 \%$ vs $5.1 \%, P=0.012)$ were significantly lower in Evolut $\mathrm{R}$ than CoreValve recipients. Evolut R significantly reduce 30-day composite safety endpoint (4.3\% vs $15.4 \%, p=0.004)$. In conclusion, advancements in transcatheter valve technologies have resulted in improved outcomes for patients undergoing TAVR with self-expanding valves. With new-generation Evolut $\mathrm{R}$, device success was high and significantly reduced 30-day composite safety endpoint after TAVR compared with CoreValve.

\section{Introduction}

Degenerative aortic stenosis (AS) is the most common valvular heart disease in adults, with a prevalence of approximately $4 \%$ in patients over 80 years of age. After the onset of symptoms (angina, syncope, or heart failure), the average survival time is 2 to 3 years, with a high risk of sudden death ${ }^{1}$. In clinical practice, more than $30 \%$ of patients with severe symptomatic AS do not undergo surgical aortic valve replacement (SAVR) due to advanced age, left ventricular dysfunction, or the presence of multiple coexisting conditions ${ }^{2,3}$. Based on recent randomized trials showing the non-inferiority of transcatheter aortic valve replacement (TAVR) compared to SAVR in high- and intermediate-risk patients, TAVR is now being increasingly used also in this lower risk population ${ }^{4-6}$. In Taiwan, the CoreValve transcatheter aortic bioprosthesis (Medtronic, Minneapolis, MN, USA) was the first commercially available valve approved in December 2012, and the second-generation self-expanding Evolut R valve (Medtronic) was available in March $2017^{7}$. To date, more than 1000 TAVR procedures using self-expanding Medtronic devices have been performed in Taiwan. The continuous device iterations, along with growing operator experience and refinement of procedural techniques, have played a major role in improving the safety and efficacy of TAVR procedures.

We performed a single-center study, comparing the Evolut $\mathrm{R}$ with its direct precursor, the CoreValve, with regard to 30-day Valve Academic Research Consortium-2 (VARC-2)-defined safety and efficacy outcomes.

\section{Methods}


Patient population. Between March 2013 and December 2020, 237 consecutive patients treated with selfexpanding TAVR were enrolled. Three patients were excluded because TAVR was performed for isolated aortic regurgitation. Remaining 234 patients with severe aortic stenosis were included in the analysis, of 117 patients with the CoreValve and 117 with the Evolut R (Figure 1). Patients were selected for TAVR when considered unsuitable or at high risk for SAVR by heart team discussion. Operative risk was calculated using the logistic European System for Cardiac Operative Risk Evaluation (EuroSCORE) score. Patient selection for TAVR was based on the approved indications for TAVR ${ }^{8}$.

Ethical approval statement. This retrospective chart review study involving human participants was in accordance with the ethical standards of the institutional and national research committee and with the 1964 Helsinki Declaration and its later amendments or comparable ethical standards. This study was approved by the Institutional Review Board of Taipei Veterans General Hospital (approval number: 202011-002BC). Informed consent was obtained from all individual participants included in the study.

Procedural details. All patients underwent TAVR with CoreValve or Evolut R prostheses as described ${ }^{8,9}$. All procedures were performed in a specially equipped hybrid operating suite. At the beginning of our experience, TAVR procedures were performed under general anesthesia. Since December 2013, local anesthesia with conscious sedation had been exclusively used for transfemoral TAVR. The standard approach for both valves was through the transfemoral route, if feasible. In patients who did not have adequate anatomy to allow safe transfemoral access, alternative access routes such as trans-subclavian, direct aortic trans-abdominal aortic, or transcarotid access were used ${ }^{9}$. Adjunct pharmacologic therapy included heparin during the procedure and aspirin ( $100 \mathrm{mg} /$ day) indefinitely and clopidogrel $(75 \mathrm{mg} /$ day $)$ for 3-6 months following the procedure. Valve size was selected according to ranges of perimeter-derived annulus diameters based on CT recommended by the manufacturer.

Echocardiographic assessment. Standardized transthoracic echocardiography was performed before and after TAVR by board-certified cardiologists. The calculation of effective orifice area (EOA) required calculation of LV stroke volume using the outer-to-outer diameter of the stented valve paired with the pulsed wave Doppler placed just apical to the stented valve recommended by Hahn et al ${ }^{10}$.

Study endpoints. All clinical endpoints of this study were defined according to the VARC-2 criteria ${ }^{11}$. "Device success" was defined as the absence of procedural mortality ( $\leq 72 \mathrm{~h}$ postprocedure) and correct positioning of a single prosthetic heart valve into the proper anatomical location and intended performance of the prosthetic heart valve [no prosthesis-patient mismatch and mean aortic valve gradient $<20 \mathrm{mmHg}$ or peak velocity $<3 \mathrm{~m} / \mathrm{s}$, and no moderate or severe prosthetic valve regurgitation (PVL)]. Following valve deployment, assessment of valve function was performed using transthoracic echocardiography. VARC-2 proposed using the AKIN system for the reporting of acute kidney injury (AKI). AKI was defined as an absolute ( 48 hours) reduction in kidney function and defined as: stage 2 increase in serum creatinine to $200-299 \%$ (2.0-2.9 $x$ increase compared with baseline) or urine output < $0.5 \mathrm{ml} / \mathrm{kg} / \mathrm{h}$ for $>12 \mathrm{~h}$ but $<24 \mathrm{~h}$ and stage $3-$ increase in serum creatinine to $>300 \%$ ( $>3 \mathrm{x}$ increase compared with baseline) or serum creatinine of $>4.0 \mathrm{mg} / \mathrm{dL}$ with an acute increase of at least $0.5 \mathrm{mg} / \mathrm{dL}$ 
or the new need for renal replacement therapy post TAVR. The 30-day-combined safety endpoint is a combined endpoint defined by VARC-2 as a composite of all-cause mortality, major stroke, life-threatening or disabling bleeding, acute stage 2 or 3 kidney injury including renal replacement therapy, major vascular complications, coronary artery obstruction requiring intervention, and repeat procedure for valve-related dysfunction.

Statistical analysis. Continuous variables were expressed as mean \pm standard deviation (SD), and analyzed with the Student's $t$ test or the Wilcoxon rank sum test, depending on the variable distribution. Categorical variables were compared using the chi-square test with Yates' correction for continuity or the Fisher's exact test. For all comparisons, $\mathrm{p}$ value $<0.05$ was considered statistically significant. The data were analyzed using SPSS software, version 24.0 (IBM, Armonk, NY, USA).

\section{Results}

Baseline characteristics. The demographic and echocardiographic characteristics are displayed in Table 1. The mean age of the population was $80.8 \pm 8.8$ years and the mean logistic EuroSCORE was $18.3 \%$. Fifty-five percent of the study population were female. Twenty-seven (11.5\%) had a bicuspid aortic valve and $9(3.8 \%)$ underwent aortic valve-in-valve procedures for failed surgical bioprosthesis. Baseline demographic characteristics did not differ between groups except that valve-in-valve procedures for failed surgical bioprosthesis $(0.9 \%$ vs. $6.8 \%, p=0.018)$ was performed significantly more often with Evolut $R$. At baseline, echocardiographic assessment of valve function showed an aortic valve area was $0.71 \pm 0.21$ $\mathrm{cm}^{2}$. The mean transvalvular pressure gradient was decreased $(47.2 \pm 19.4$ vs. $36.8 \pm 15.5 \mathrm{mmHg}, \mathrm{p}<$ $0.001)$ and left ventricular ejection fraction was increased $(53.7 \pm 11.0 \%$ vs. $56.6 \pm 9.9 \%, p=0.027)$ in Evolut R group. 
Table 1

Baseline characteristics and echocardiographic assessment.

\begin{tabular}{|c|c|c|c|c|}
\hline & $\begin{array}{l}\text { All patients } \\
(n=234)\end{array}$ & $\begin{array}{l}\text { CoreValve } \\
(n=117)\end{array}$ & $\begin{array}{l}\text { Evolut R } \\
(n=117)\end{array}$ & $P$ value \\
\hline Age, years & $80.8 \pm 8.8$ & $80.6 \pm 8.6$ & $80.9 \pm 9.2$ & 0.791 \\
\hline Female & $129(55.1)$ & $62(53.0)$ & $67(57.3)$ & 0.513 \\
\hline $\mathrm{BMI}, \mathrm{kg} / \mathrm{m}^{2}$ & $24.5 \pm 4.1$ & $24.5 \pm 4.3$ & $24.5 \pm 4.0$ & 0.929 \\
\hline BSA, $\mathrm{m}^{2}$ & $1.62 \pm 0.20$ & $1.63 \pm 0.20$ & $1.61 \pm 0.19$ & 0.417 \\
\hline LogEuroSCORE (\%) & $18.3 \pm 15.1$ & $18.5 \pm 15.0$ & $18.2 \pm 15.2$ & 0.884 \\
\hline Hypertension & $178(76.1)$ & $85(72.6)$ & $93(79.5)$ & 0.222 \\
\hline Diabetes & $80(34.2)$ & $45(38.5)$ & $35(29.9)$ & 0.101 \\
\hline Coronary artery disease & $104(44.4)$ & $49(41.9)$ & $55(47.0)$ & 0.432 \\
\hline Prior PCl & $83(35.5)$ & $37(31.6)$ & $46(39.3)$ & 0.221 \\
\hline Prior CABG & $11(4.7)$ & $6(5.1)$ & $5(4.3)$ & 0.759 \\
\hline Prior MI & $13(5.6)$ & $7(6.0)$ & $6(5.1)$ & 0.776 \\
\hline Cerebrovascular disease & $47(20.1)$ & $20(17.1)$ & $27(23.1)$ & 0.269 \\
\hline Peripheral artery disease & $59(25.2)$ & $25(21.4)$ & $34(29.1)$ & 0.233 \\
\hline COPD & $33(14.1)$ & $17(14.5)$ & $16(13.7)$ & 0.852 \\
\hline Prior pacemaker & $8(3.4)$ & $3(2.6)$ & $5(4.3)$ & 0.474 \\
\hline Atrial fibrillation & $55(23.5)$ & $31(26.5)$ & $24(20.5)$ & 0.508 \\
\hline eGFR, $\mathrm{ml} / \mathrm{min}$ & $42.1 \pm 21.9$ & $41.5 \pm 22.3$ & $43.0 \pm 21.4$ & 0.612 \\
\hline Dialysis & $21(9.0)$ & $12(10.3)$ & $9(7.6)$ & 0.495 \\
\hline Bicuspid aortic valve & $27(11.5)$ & $13(11.1)$ & $14(12.0)$ & 0.857 \\
\hline Valve-in-valve procedure & $9(3.8)$ & $1(0.9)$ & $8(6.8)$ & 0.018 \\
\hline \multicolumn{5}{|c|}{ Echocardiographic assessment } \\
\hline AVA, $\mathrm{cm}^{2}$ & $0.71 \pm 0.21$ & $0.69 \pm 0.23$ & $0.73 \pm 0.19$ & 0.137 \\
\hline \multicolumn{5}{|c|}{$\begin{array}{l}\text { Values are mean } \pm \text { SD or } n(\%) \text {. AR, aortic regurgitation; AVA, aortic valve area; } B M I \text {, body mass index; } \\
\text { BSA, body surface area; CABG, coronary artery bypass surgery; COPD, chronic obstruction pulmonary } \\
\text { disease; eGFR, estimated glomerular filtration rate; EuroSCORE, European System for Cardiac } \\
\text { Operative Risk Evaluation; LVEF, left ventricular ejection fraction; MI, myocardial infarction; MR, mitral } \\
\text { regurgitation; PAP, pulmonary artery pressure; PCl, percutaneous coronary intervention; PG, pressure } \\
\text { gradient. }\end{array}$} \\
\hline
\end{tabular}




\begin{tabular}{|c|c|c|c|c|}
\hline & $\begin{array}{l}\text { All patients } \\
(n=234)\end{array}$ & $\begin{array}{l}\text { CoreValve } \\
(n=117)\end{array}$ & $\begin{array}{l}\text { Evolut } R \\
(\mathrm{n}=117)\end{array}$ & $P$ value \\
\hline Mean PG, mm Hg & $42.1 \pm 18.2$ & $47.2 \pm 19.4$ & $36.8 \pm 15.5$ & $<0.001$ \\
\hline LVEF, \% & $55.3 \pm 10.5$ & $53.7 \pm 11.0$ & $56.6 \pm 9.9$ & 0.041 \\
\hline Moderate to severe AR & $39(16.7)$ & $22(18.8)$ & $17(14.5)$ & 0.165 \\
\hline Moderate to severe MR & $39(16.7)$ & $21(17.9)$ & $18(15.4)$ & 0.343 \\
\hline PAP, mm Hg & $42.4 \pm 16.4$ & $44.5 \pm 16.5$ & $39.9 \pm 15.8$ & 0.028 \\
\hline \multicolumn{5}{|l|}{ Computed tomography data } \\
\hline Perimeter-derived annulus diameter, $\mathrm{mm}$ & $23.2 \pm 2.6$ & $24.0 \pm 2.7$ & $22.3 \pm 2.3$ & $<0.001$ \\
\hline \multicolumn{5}{|c|}{$\begin{array}{l}\text { Values are mean } \pm \text { SD or } n(\%) \text {. AR, aortic regurgitation; AVA, aortic valve area; } B M I \text {, body mass index; } \\
\text { BSA, body surface area; } C A B G \text {, coronary artery bypass surgery; COPD, chronic obstruction pulmonary } \\
\text { disease; eGFR, estimated glomerular filtration rate; EuroSCORE, European System for Cardiac } \\
\text { Operative Risk Evaluation; } L V E F, \text { left ventricular ejection fraction; MI, myocardial infarction; MR, mitral } \\
\text { regurgitation; PAP, pulmonary artery pressure; PCl, percutaneous coronary intervention; } P G \text {, pressure } \\
\text { gradient. }\end{array}$} \\
\hline
\end{tabular}

Procedural characteristics. Procedural characteristics are presented in Table 2. Conscious sedation was used more often in the Evolut R group $(69.2 \%$ vs. $89.7 \%, \mathrm{p}<0.001)$, whereas non-transfemoral access was performed numerically less frequent in the Evolut $R$ group $(7.8 \%$ vs. $2.6 \%, p=0.076)$. Pre-dilatation was performed more often in the CoreValve group ( $78.6 \%$ vs. $51.3 \%, p<0.001)$, whereas post-dilatation was comparable between 2 groups ( $4.3 \%$ vs. $3.4 \%, p=0.725)$. The mean perimeter-derived diameter of aortic annulus was smaller in Evolut R group ( $24.0 \pm 2.7$ vs. $22.3 \pm 2.2 \mathrm{~mm}, \mathrm{p}<0.001)$, thus resulting in the use of a smaller prosthesis size in Evolut $\mathrm{R}$ group. Twenty-three-millimeter valves were more frequently used in the Evolut $R$ group $(1.7 \%$ vs. $14.5 \%, p<0.001)$, whereas 31 - or 34 -mm prosthesis was more frequent in the CoreValve group $(16.2 \%$ vs. $4.3 \%, p<0.001)$. The mean contrast media volumes were significantly lower $(123.6 \pm 55.1$ vs. $72.2 \pm 32.5 \mathrm{ml}, \mathrm{p}<0.001)$ in the Evolut $\mathrm{R}$ recipients. 
Table 2

Procedural characteristics.

\begin{tabular}{|c|c|c|c|c|}
\hline & $\begin{array}{l}\text { All patients } \\
(n=234)\end{array}$ & $\begin{array}{l}\text { CoreValve } \\
(n=117)\end{array}$ & $\begin{array}{l}\text { Evolut R } \\
(n=117)\end{array}$ & $P$ value \\
\hline Valve size & & & & $<0.001$ \\
\hline $23 \mathrm{~mm}$ & $19(8.1)$ & $2(1.7)$ & $17(14.5)$ & \\
\hline $26 \mathrm{~mm}$ & $98(41.9)$ & $41(35.0)$ & $57(48.7)$ & \\
\hline $29 \mathrm{~mm}$ & $93(39.7)$ & $55(47.0)$ & $38(32.5)$ & \\
\hline 31 or $34 \mathrm{~mm}$ & $24(10.3)$ & $19(16.2)$ & $5(4.3)$ & \\
\hline Conscious sedation & $186(79.5)$ & $81(69.2)$ & 105 (89.7) & $<0.001$ \\
\hline Access & & & & 0.240 \\
\hline Transfemoral & $222(94.9)$ & 108 (92.2) & 114 (97.4) & \\
\hline Trans-subclavian & $3(1.3)$ & $3(2.6)$ & $0(0.0)$ & \\
\hline Trans-aortic & $3(1.3)$ & $2(1.7)$ & $1(0.9)$ & \\
\hline Trans-carotid & $5(2.1)$ & $3(2.6)$ & $2(1.8)$ & \\
\hline Trans-abdominal aortic & $1(0.4)$ & $1(0.9)$ & $0(0.0)$ & \\
\hline Oversizing by perimeter, $\%$ & $18.9 \pm 7.9$ & $17.8 \pm 8.4$ & $19.9 \pm 7.2$ & 0.044 \\
\hline Balloon pre-dilation & $153(65.4)$ & $92(78.6)$ & $60(51.3)$ & $<0.001$ \\
\hline Balloon post-dilation & $9(3.9)$ & $5(4.3)$ & $4(3.4)$ & 0.725 \\
\hline Contrast volume, ml & $97.8 \pm 51.8$ & $123.6 \pm 55.1$ & $72.2 \pm 32.5$ & $<0.001$ \\
\hline
\end{tabular}

VARC-2 outcome at 30 days. Thirty-day outcome according to VARC-2 criteria are presented in Table 3. At 30-day follow-up, all-cause mortality was overall low (8/234, 3.4\%) and was numerically lower amongst patients treated with Evolut R ( $5.1 \%$ vs. $1.7 \%, p=0.134)$. Stroke $(4.3 \%$ vs. $0 \%, p=0.024)$ and the need for emergent conversion to open surgery $(5.1 \%$ vs. $0 \%, p=0.012)$ were significantly lower in Evolut $R$ than CoreValve recipients. There was a numerically lower frequency of major vascular complications $(5.1 \%$ vs. $0.9 \%, p=0.055)$, and acute kidney injury, stage 2 or $3(8.6 \%$ vs. $3.7 \%, p=0.159)$ amongst Evolut $R$ recipients. The need for a second valve was numerically reduced with the recapturable Evolut $\mathrm{R}$ system $(2.6 \%$ vs. $0.9 \%, p=0.147)$. The rate of new pacemaker implantation was low $(3.5 \%$ vs. $1.8 \%, p=0.410)$ and comparable between groups. None developed valve-related dysfunction requiring repeat procedure, such as balloon aortic valvuloplasty, TAVR, or SAVR. Device success was achieved in $93.2 \%$ of CoreValve 
recipients and $97.4 \%$ amongst patients treated with Evolut $R(p=0.123)$. Composite safety endpoint occurred in $15.4 \%$ of CoreValve patients and $4.3 \%$ of Evolut R patients $(p=0.004)$ (Figure 2$)$. 
Table 3

Thirty-day outcomes according to Valve Academic Research Consortium-2 (VARC-2) criteria and hemodynamic performance.

\begin{tabular}{|c|c|c|c|c|}
\hline Variables & $\begin{array}{l}\text { All } \\
\text { patients } \\
(n= \\
234)\end{array}$ & $\begin{array}{l}\text { CoreValve } \\
(n=117)\end{array}$ & $\begin{array}{l}\text { Evolut } \\
\mathrm{R} \\
(\mathrm{n}= \\
117)\end{array}$ & $\begin{array}{l}\mathrm{P} \\
\text { value }\end{array}$ \\
\hline \multicolumn{5}{|l|}{ VARC-2 defined outcomes at 30 days } \\
\hline All-cause death & $8(3.4)$ & $6(5.1)$ & $2(1.7)$ & 0.134 \\
\hline Cardiovascular mortality & $5(2.1)$ & $3(2.6)$ & $2(1.7)$ & 0.618 \\
\hline Stroke & $5(2.1)$ & $5(4.3)$ & $0(0.0)$ & 0.024 \\
\hline Major vascular complication & $7(3.0)$ & $6(5.1)$ & $1(0.9)$ & 0.055 \\
\hline Conversion to open surgery & $6(2.6)$ & $6(5.1)$ & 0 & 0.012 \\
\hline Need for a second valve & $4(1.7)$ & $3(2.6)$ & $1(0.9)$ & 0.273 \\
\hline Acute kidney injury, stage & $13(6.1)$ & $9(8.6)$ & $4(3.7)$ & 0.147 \\
\hline \multicolumn{5}{|l|}{2 or $3^{a}$} \\
\hline Coronary obstruction & $3(1.3)$ & $2(1.7)$ & $1(0.9)$ & 0.311 \\
\hline New pacemaker implantation ${ }^{\mathrm{b}}$ & $6(2.7)$ & $4(3.5)$ & $2(1.8)$ & 0.410 \\
\hline $\begin{array}{l}\text { Valve-related dysfunction requiring repeat procedure } \\
\text { (BAV, TAVR, or SAVR) }\end{array}$ & 0 & 0 & 0 & NA \\
\hline Device success & $\begin{array}{l}223 \\
(95.3)\end{array}$ & $\begin{array}{l}109 \\
(93.2)\end{array}$ & $\begin{array}{l}114 \\
(97.4)\end{array}$ & 0.123 \\
\hline Composite safety endpoint & $23(9.8)$ & $18(15.4)$ & $5(4.3)$ & 0.004 \\
\hline \multicolumn{5}{|l|}{ Echocardiographic assessment } \\
\hline Effective orifice area & $\begin{array}{l}1.72 \pm \\
0.38\end{array}$ & $\begin{array}{l}1.70 \pm \\
0.38\end{array}$ & $\begin{array}{l}1.74 \pm \\
0.37\end{array}$ & 0.467 \\
\hline Mean PG, mm Hg & $\begin{array}{l}7.7 \pm \\
3.9\end{array}$ & $8.2 \pm 3.9$ & $\begin{array}{l}7.1 \pm \\
3.8\end{array}$ & 0.032 \\
\hline
\end{tabular}

Values are mean \pm SD or $n(\%)$. BAV, Balloon aortic valvuloplasty; PG, pressure gradient, $P V L$, paravalvular leak; TAVR, transcatheter aortic valve replacement; SAVR, surgical aortic valve replacement.

a excluding patients on dialysis.

${ }^{b}$ excluding patients with prior permanent pacemakers. 


\begin{tabular}{|c|c|c|c|c|}
\hline Variables & $\begin{array}{l}\text { All } \\
\text { patients } \\
(n= \\
234)\end{array}$ & $\begin{array}{l}\text { CoreValve } \\
(n=117)\end{array}$ & $\begin{array}{l}\text { Evolut } \\
R \\
(n= \\
117)\end{array}$ & $\begin{array}{l}P \\
\text { value }\end{array}$ \\
\hline Peak PG, mm Hg & $\begin{array}{l}14.5 \pm \\
7.4\end{array}$ & $15.6 \pm 7.4$ & $\begin{array}{l}12.9 \pm \\
7.0\end{array}$ & 0.016 \\
\hline \multicolumn{5}{|c|}{ Post-procedural PVL } \\
\hline Moderate & $7(3.0)$ & $5(4.3)$ & $2(1.7)$ & 0.201 \\
\hline Severe & 0 & 0 & 0 & \\
\hline \multicolumn{5}{|c|}{$\begin{array}{l}\text { Values are mean } \pm \text { SD or } n(\%) \text {. BAV, Balloon aortic valvuloplasty; } P G \text {, pressure gradient, } P V L \text {, } \\
\text { paravalvular leak; TAVR, transcatheter aortic valve replacement; SAVR, surgical aortic valve } \\
\text { replacement. }\end{array}$} \\
\hline \multicolumn{5}{|c|}{ a excluding patients on dialysis. } \\
\hline
\end{tabular}

Hemodynamic performance. Figure 3 shows the baseline and 30-day EOA and mean pressure gradient for CoreValve and Evolut R. There were no significant differences in EOA between both groups (1.70 \pm 0.38 vs. $\left.1.74 \pm 0.37 \mathrm{~cm}^{2}, p=0.467\right)$. Post-procedural mean pressure gradient $(8.2 \pm 3.9$ vs. $7.1 \pm 3.8$ $\mathrm{mmHg}, \mathrm{p}=0.032)$ and peak pressure gradient $(15.6 \pm 7.4 \mathrm{vs} .12 .9 \pm 7.0 \mathrm{mmHg}, \mathrm{p}=0.016)$ at 30 days were significantly lower in Evolut R than CoreValve (Table 3). Moderate PVL was observed in $4.3 \%$ in the CoreValve group and $1.7 \%$ in the Evolut $\mathrm{R}$ recipients and none of both groups developed severe PVL.

\section{Discussion}

During the past several years, technological advancement of Evolut $\mathrm{R}$ was built on the well-established foundation of the CoreValve platform, fortified with lower delivery profile (14-16 French) to reduce vascular complications and alternative TAVR access necessity, enhanced Nitinol frame geometry to enable better housing inside the aortic root, and a complete recapturable platform that allows optimized implantation depth upon deployment. Our results support short-term efficacy and safety performance of the Evolut-R compare with the CoreValve. Evolut $\mathrm{R}$ significantly reduce 30-day composite safety endpoint, driven by numerically lower deaths, major stroke, life-threatening or disabling bleeding, and acute stage 2 or 3 kidney injury including renal replacement therapy.

The InLine sheath used in the Evolut R system has a lower profile (14-16 French) than CoreValve (18 French), which lowered the need for alternative TAVR access, which has historically been associated with inferior outcomes in patients undergoing TAVR, from 7.7-2.6\%. Pre-dilatation was observed significantly more often in the CoreValve group, which may be responsible for longer procedure duration and increased 
contrast agent administration. The higher volume of contrast use is one of the underlying mechanisms leading to acute kidney injury which remains one of the strongest predictors of short- and long-term mortality after TAVR.

Valve malposition may still occur even after all necessary precautions have been taken, while prosthesis migration and embolization were associated with a four-fold higher mortality and three-fold higher stroke rate at 30 days $^{12}$. Compared to CoreValve, a key feature of the Evolut- $R$ is the option to fully recapture and to reposition the valve during deployment. There were 3 cases $(2.6 \%)$ in the CoreValve treated patient requiring the implantation of a second valve, and one (0.9\%) in the Evolut R group. In addition, the option to recapture allowed a less ventricular implantation depth, resulting in a numerically lower incidence of new pacemaker implantation and moderate PVL in the Evolut $\mathrm{R}$ recipients.

Left ventricular perforation is the most serious complications of TAVR, usually occurs as a direct trauma by the Amplatz Super Stiff guidewire, which was used exclusively for the deployment of CoreValve. Amplatz. Super Stiff guidewire are not designed for TAVR procedures and the operators must bend the wire to achieve the optimal shape to sit safely in the ventricle for TAVR, during which procedure the central core can be damaged or the desired shape may not be achieved, A pooled analysis of causes of perioperative mortality after TAVR (12 studies examining 1223 patients) showed that $10.1 \%$ of deaths at one month were due to pericardial tamponade while $39 \%$ of "in-lab" mortality was due to cardiac perforation causing pericardial tamponade ${ }^{13}$. Notably, the adoption of a dedicated pre-shaped Confida Brecker guidewire, features a continuous, tapered core and pre-shaped curve, in the Evolut R recipients reduce the risk of left ventricular perforation, which necessitated emergent cardiac surgery, from $5.1 \%$ in the CoreValve group to none in the Evolut $\mathrm{R}$ recipients.

The primary goal of TAVR is to achieve the maximum orifice area with a minimum flow velocity. Given severe prosthesis-patient mismatch (PPM) was associated with increased risk of 1-year mortality (hazard ratio: 1.19) and heart failure re-hospitalization (hazard ratio: 1.12) following TAVR in 62,125 patients enrolled in the STS/ACC TVT Registry ${ }^{14}$, there has been a concern regarding PPM in Asian patients with small aortic annulus. Studies in east Asian populations demonstrated Sapien 3 valve had smaller EOA $\left(2.07 \pm 0.61 \text { vs. } 1.70 \pm 0.49 \mathrm{~cm}^{2}, \mathrm{p}<0.001\right)^{15}$ and caused PPM about 1.92 times $^{16}$ more than Sapien XT valve. Thus, TAVR with supra-annular self-expanding was associated with superior hemodynamic outcomes compared with balloon-expandable valves in patients with small aortic annulus. These findings pave the way for further trials regarding appropriate prosthesis selection for TAVR in patients with in East Asian population with small aortic annulus.

\section{Limitations}

Our study was only a single-center investigation and was limited by its retrospective and observational design. In addition, the results of CoreValve could have been affected by the learning curve of TAVR in the early stages, thus the benefit of Evolut R might have been overstated to some extent. 


\section{Conclusions}

Advancements in valve technologies with the option to recapture and reposition of Evolut $\mathrm{R}$, the introduction of InLine sheath with a lower profile, and dedicated pre-shaped guidewires have resulted in improved outcomes for patients undergoing TAVR with supra-annular self-expanding valves. Compared to CoreValve, Evolut R significantly reduce 30-day composite safety endpoint, driven by significantly lower stroke and life-threatening or disabling bleeding, as well as numerically lower deaths and acute stage 2 or 3 kidney injury including renal replacement therapy.

\section{Declarations}

\section{Data availability}

Patient data is unavailable due to protection reasons

\section{Acknowledgements}

The authors are grateful for doctor Nai-Yuan Wu at Institute of Biomedical Informatics, National YangMing Chao-Tung University, Taipei, for providing statistical analysis.

\section{Author contributions}

CC Kuo, and YH Chen designed the study and wrote the manuscript. IM Chen and SM Lin involved in the data curation. CC Kuo, HB Leu and PL Chen performed statistical analysis and interpretation of data. $\mathrm{HH}$ Chang and $\mathrm{YH}$ Chen conducted the literature review and supervised the study. All authors discussed the results, reviewed the manuscript and approved the final version.

\section{Competing Interests Statement}

Dr. Ying-Hwa Chen and Dr. Hsiao-Huang Chang are proctors for the Medtronic CoreValve and Evolut R. All other authors have reported that they have no relationships relevant to the contents of this paper to disclose.

\section{References}

1. Bonow R. O., et al. 2008 Focused update incorporated into the ACC/AHA 2006 guidelines for the management of patients with valvular heart disease: a report of the American College of Cardiology/American Heart Association Task Force on Practice Guidelines (Writing Committee to Revise the 1998 Guidelines for the Management of Patients with Valvular Heart Disease): endorsed by the Society of Cardiovascular Anesthesiologists, Society for Cardiovascular Angiography and Interventions, and Society of Thoracic Surgeons. Circulation. 118, e523-e661 (2008).

2. Lung, B., et al. Decision-making in elderly patients with severe aortic stenosis: why are so many denied surgery?. Eur. Heart. J. 26, 2714-2720 (2005). 
3. Bach, D. S., Siao, D., Girard, S. E., Duvernoy, C., McCallister, B. D., Jr, \& Gualano S. K. Evaluation of patients with severe symptomatic aortic stenosis who do not undergo aortic valve replacement. Circ. Cardiovasc. Qual. Outcomes. 2, 533-539 (2009).

4. Smith, C. R., et al. PARTNER Trial Investigators. Transcatheter versus surgical aortic-valve replacement in high-risk patients. N. Engl. J. Med. 364, 2187-2198 (2011).

5. Leon, M. B., et al. PARTNER 2 Investigators. Transcatheter or surgical aortic-valve replacement in intermediate-risk patients. N. Engl. J. Med. 374, 1609-1620 (2016).

6. Mack, M. J., et al. Transcatheter aortic valve replacement with a balloon-expandable valve in low-risk patients. N. Engl. J. Med. 380, 1695-1705 (2019).

7. Manoharan, G., et al. Treatment of symptomatic severe aortic stenosis with a novel resheathable supra-annular self-expanding transcatheter aortic valve system. JACC. Cardiovasc. Interv. 8, 13591367 (2015).

8. Adams, D. H., et al. Transcatheter aortic-valve replacement with a self-expanding prosthesis. N. Engl. J. Med. 370, 1790-1798 (2014).

9. Chen, Y. H., et al. Procedural characteristics and outcomes of transcatheter aortic valve implant: a single center experience of the first 100 inoperable or high surgical risk patients with severe aortic stenosis. Acta. Cardiol. Sin. 33, 339-349 (2017).

10. Hahn, R. T., et al. Comprehensive echocardiographic assessment of normal transcatheter valve function. JACC. Cardiovasc. Imaging. 12, 25-34 (2019).

11. Kappetein, A. P., et al. Updated standardized endpoint definitions for transcatheter aortic valve implantation: the Valve Academic Research Consortium-2 consensus document. J. Am. Coll. Cardiol. 60, 1438-1454 (2012).

12. Kim, W. K., et al. Incidence and outcome of peri-procedural transcatheter heart valve embolization and migration: the TRAVEL registry (TranscatheteR HeArt Valve EmboLization and Migration). Eur. Heart. J. 40, 3156-3165 (2019).

13. Moreno, R., et al. Causes of peri-operative mortality after transcatheter aortic valve implantation: a pooled analysis of 12 studies and 1223 patients. J. Invasive. Cardiol. 23, 180-184 (2011).

14. Herrmann, H. C., et al. Prosthesis-patient mismatch in patients undergoing transcatheter aortic valve replacement: from the STS/ACC TVT registry. J. Am. Coll. Cardiol. 72, 2701-2711 (2018).

15. Kook, H., et al. Comparing the Procedural and Clinical Outcomes of Sapien XT and Sapien 3 Valves in Transcatheter Aortic Valve Replacement in Korean Patients. Korean. Circ. J. 50, 907-922 (2020).

16. Miyasaka, M., et al. Incidence and predictors of prosthesis-patient mismatch after TAVI using SAPIEN 3 in Asian: differences between the newer and older balloon-expandable valve. Open. Heart. 8, e001531 (2021).

\section{Figures}




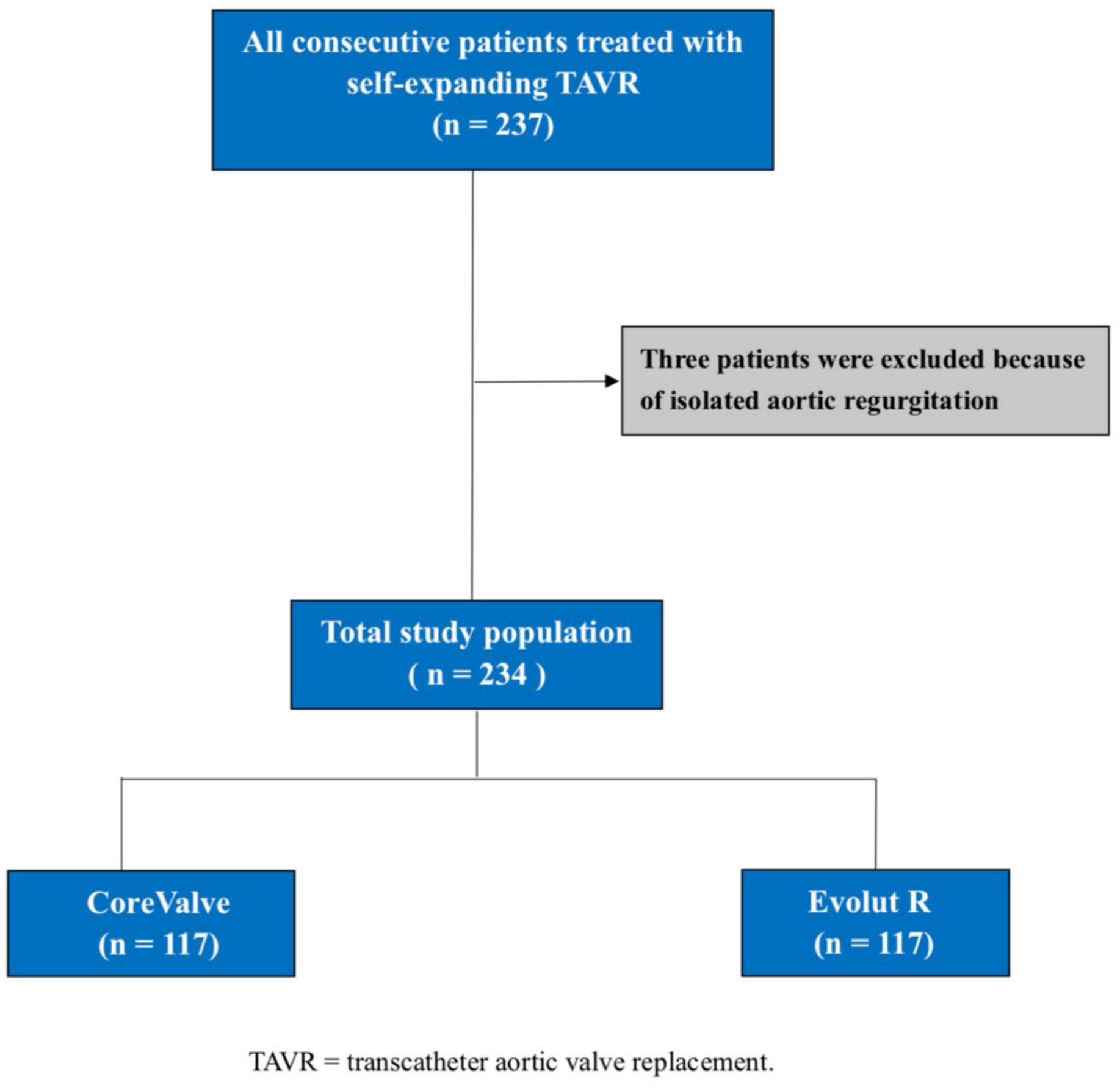

\section{Figure 1}

Study population. Total 234 patients underwent transcatheter aortic valve replacement for severe aortic stenosis, of 117 patients with CoreValve and 117 with Evolut R. 


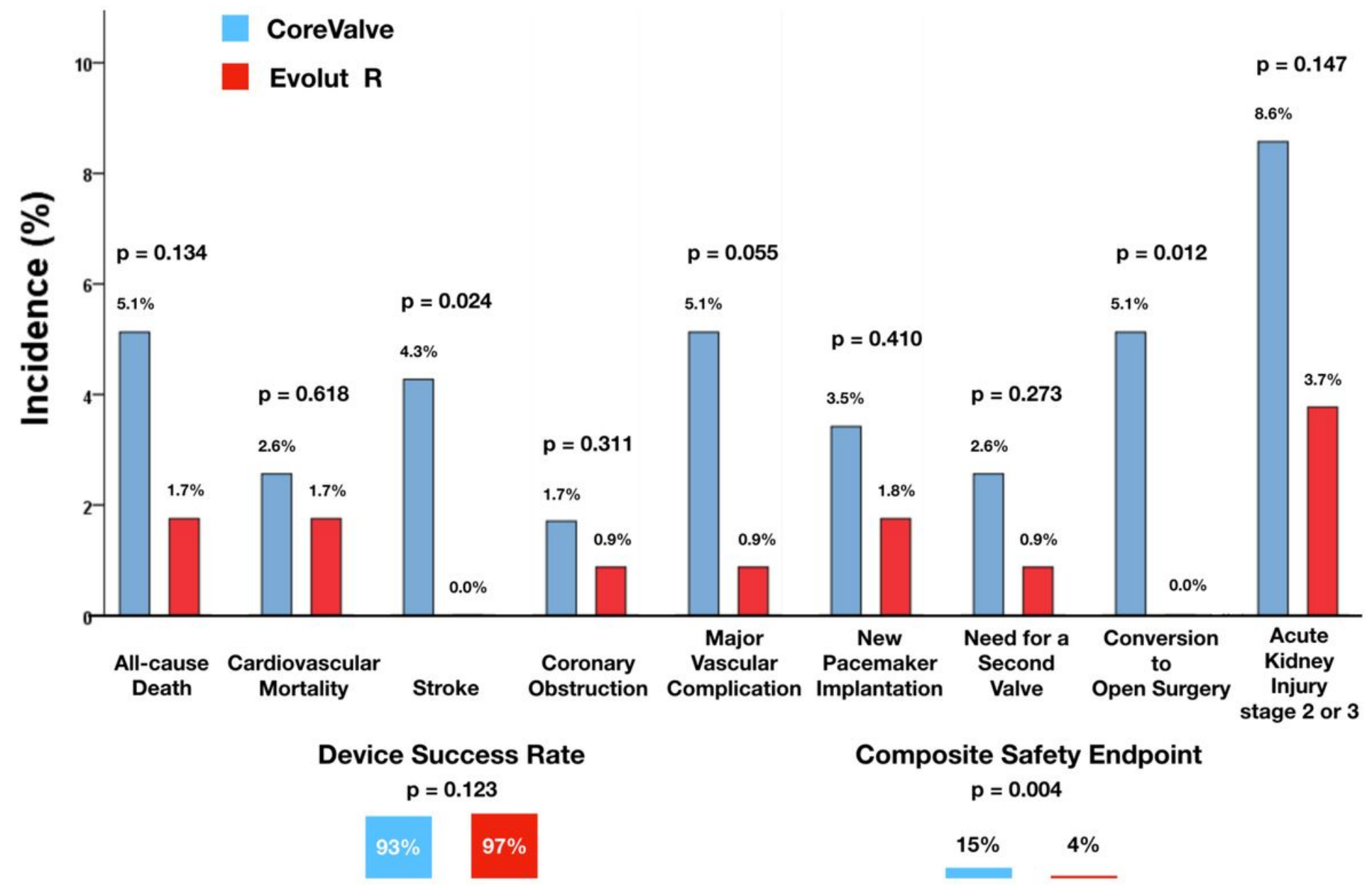

Figure 2

VARC-2 outcome at 30 days. Thirty-day outcome according to Valve Academic Research Consortium-2 Criteria between CoreValve and Evolut R system. 
A
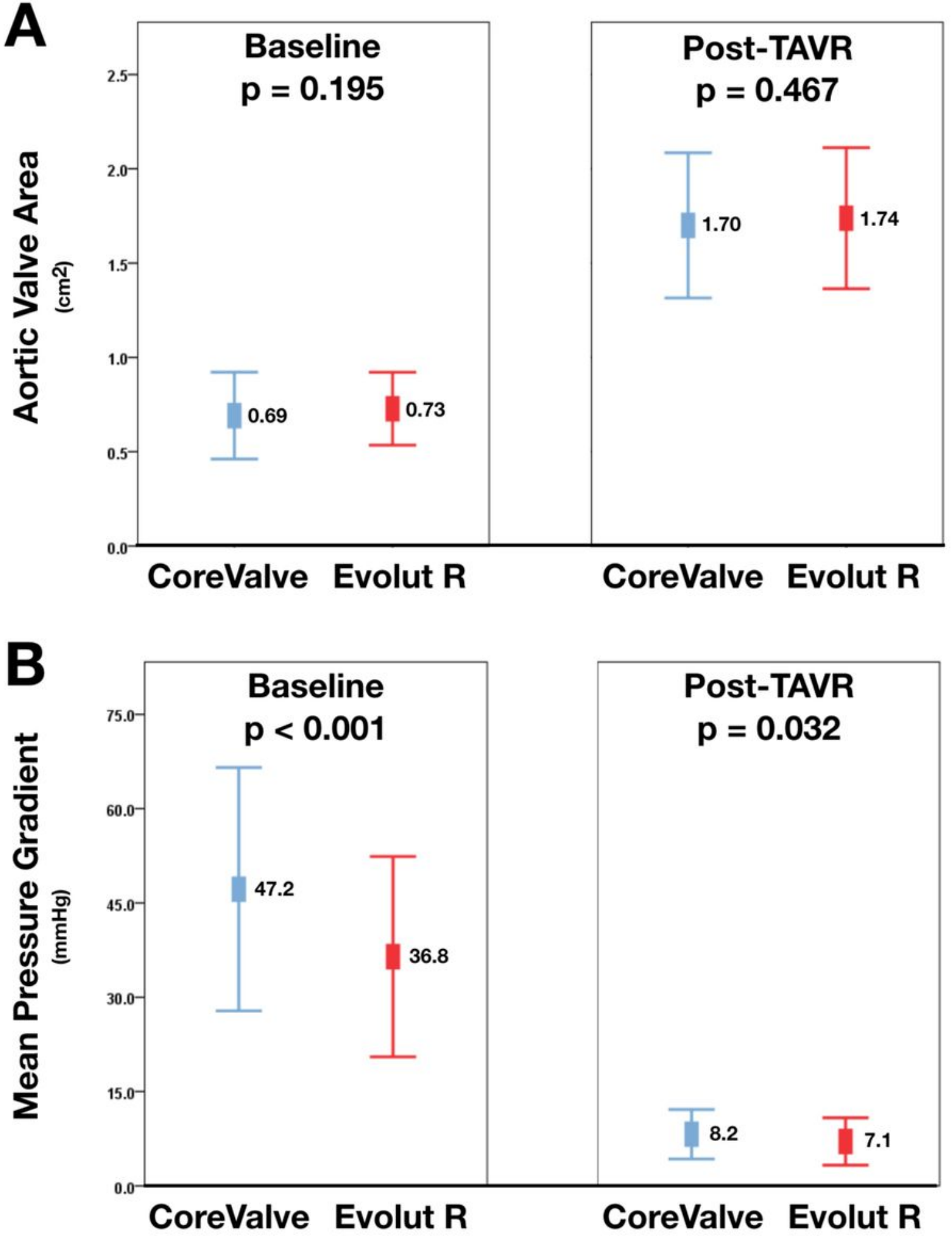

Figure 3

Hemodynamic performance. Baseline and Post-transcatheter aortic valve replacement hemodynamic performance between CoreValve and Evolut R. (A) aortic valve area. (B) mean pressure gradient 